\title{
Disain Fasilitas Sisi Udara dan Operasional Bandar Udara Jenderal Besar Soedirman, Purbalingga
}

\author{
Muhammad Yuanto Permana dan Ervina Ahyudanari
}

Departemen Teknik Sipil, Institut Teknologi Sepuluh Nopember (ITS)

Corresponding Author: ervina@ce.its.ac.id

\begin{tabular}{|c|c|}
\hline ARTIKEL INFO & ABSTRAK \\
\hline $\begin{array}{l}\text { Kata Kunci } \\
\text { Fasilitas Sisi Udara, Operasional } \\
\text { Bandara, Runway, Taxiway, Apron, } \\
\text { Bandara Jenderal Besar Soedirman, } \\
\text { Purbalingga, Wirasaba }\end{array}$ & $\begin{array}{l}\text { PT. Angkasa Pura II akan membangun Bandara Jenderal Besar } \\
\text { Soedirman di Purbalingga dengan kelas bandara III C, menggunakan } \\
\text { lahan yang dimiliki oleh TNI AU di Wirasaba, Kab. Purbalingga. Adanya } \\
\text { pembangunan bandara ini perlu dilengkapi dengan studi detil disain } \\
\text { fasilitas sisi udara yang meliputi runway, taxiway, dan apron. Pada disain } \\
\text { fasilitas sisi udara pada Bandara Jenderal Besar Soedirman ini dilakukan } \\
\text { pengumpulan data penumpang dari proyeksi pengguna moda transportasi } \\
\text { kereta eksekutif pada Stasiun Purwokerto. Dari hasil analisis yang } \\
\text { dilakukan, didapatkan jumlah penumpang per-hari. Pesawat rencana } \\
\text { untuk disain ini adalah pesawat ATR 72-600, dengan kapasitas } 68 \text { orang } \\
\text { penumpang. Setelah itu dilakukan perhitungan kapasitas runway } \\
\text { didapatkan bahwa dibutuhkan single runway untuk melayani pergerakan } \\
\text { pesawat pada Bandara Jenderal Besar Soedirman. Disain fasilitas sisi } \\
\text { udara ini juga memperhitungkan kawasan keselamatan operasional } \\
\text { penerbangannya, agar dapat dilakukan disain pengembangan terhadap } \\
\text { bandara ini. Mengingat bandara yang sudah ada sebelumnya yaitu } \\
\text { Bandara Tunggul Wulung Cilacap tidak memungkinkan dilakukannya } \\
\text { pengembangan karena terdapat cerobong asap pembangkit listrik tenaga } \\
\text { uap yang menjulang, sehingga Bandara Jenderal Besar Soedirman ini } \\
\text { yang nantinya akan terus dikembangkan }\end{array}$ \\
\hline
\end{tabular}

\section{PENDAHULUAN}

Bandar Udara Jenderal Besar Soedirman adalah bandara yang nantinya akan dibangun di Kabupaten Purbalingga, dibangun dengan tujuan memanfaatkan dan mengembangkan Pangkalan Udara (Lanud) TNI AU Wirasaba menjadi penerbangangan sipil/komerial, dengan didukung Keputusan Menteri 160 Tahun 2017 tentang Percepatan Pengoperasian Bandar Udara Jenderal Besar Soedirman di Wirasaba [1]. Sebelumnya sudah ada bandar udara di dekat Bandar Udara Jenderal Besar Soedirman yaitu Bandara Tunggul Wulung, namun mengingat kondisi sekitar Bandar Tunggul Wulung yang tidak memungkinkan adanya pengembangan lebih lanjut, maka akan dibangun bandar udara baru yang potensi pengembangannya bagus. Sehingga penulis akan merencanakan fasilitas sisi udara dan operasional Bandar Udara Jenderal Besar Soedirman berdasarkan peraturan yang berlaku.

Tujuan utama studi ini adalah disain geometrik, perkerasan, dan drainase Bandara JB. Soedirman, juga analisis potensi rute yang memungkinkan dilayani Bandara JB. Soedirman.

\section{METODOLOGI}

Dalam memprediksi permintaan angkutan udara ini mengunakan persamaan ekonometrik yang didapatkan dari parameter jumlah penduduk dan PDRB. Dengan metode ini prakiraan angkutan udara dilakukan dengan mempertimbangkan faktor faktor yang mempengaruhinya. Faktor-faktor ini umumnya faktor pasar atau ekonomi, sehingga sering disebut juga teknik ekonometri. Terdapat teknik-teknik yang sangat bervariasi yang digunakan dalam model ekonometrik untuk disain bandar udara. Teknik-teknik analisa regresi berganda dan sederhana sering digunakan pada variasi peramalan untuk memastikan hubungan di antara peubah terikat dan peubah bebas seperti pertumbuhan ekonomi dan jumlah penduduk, faktor-faktor pasar, dan persaingan antara moda transportasi yang berbeda.

Untuk data data terkait kondisi lingkungan sekitar Bandara JB. Soedirman didapatkan dari BAPPEDA Kab. Purbalingga yang selanjutnya akan dilakukan perhitungan kebutuhan untuk disain fasilitas sisi udara bandara. 


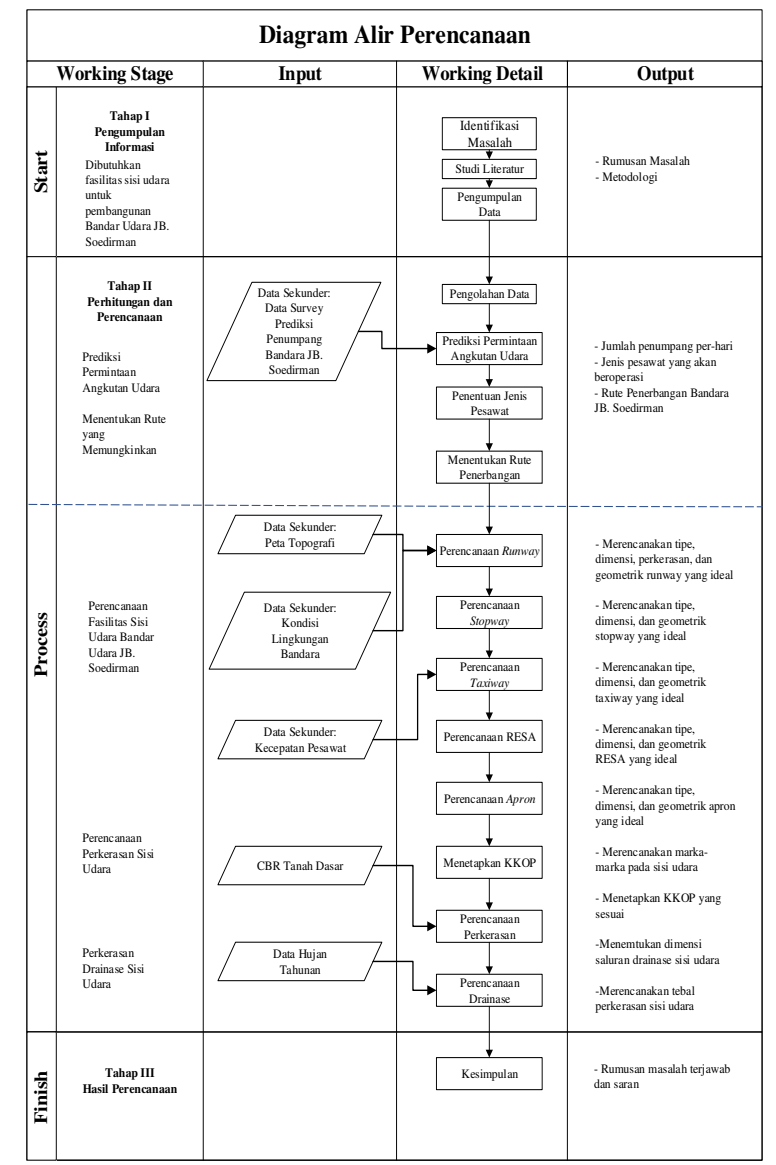

Gambar 1. Bagan Alir Metodologi Penelitian.

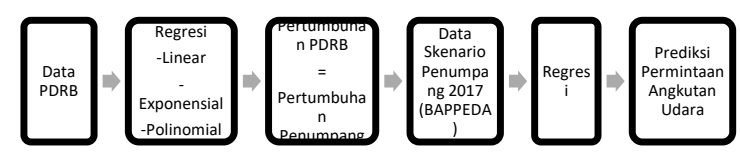

Gambar 2. Bagan Alir Perkiraan Potensi Penumpang Bandara JB. Soedirman.

Dalam merencanakan rute yang memungkinkan pada Bandar Udara Jenderal Besar Soedirman dilakukan melalui kemampuan jarak terbang pesawat yang sudah direncanakan yang kemudian akan dilakukan perhitungan biaya operasional dari moda kendaraan yang sudah ada. Dalam studi ini yang dibandingkan adalah moda mobil, pesawat dan moda kereta. Ketiga moda tersebut nantinya akan dihitung perbandingannya. Untuk biaya operasional pesawat sebelumnya sudah ada perhitungan untuk ATR 72-600 [2]. Jika moda pesawat akan lebih murah dari moda mobil/kereta, maka rute tersebut akan menjadi rute yang memungkinkan ada dalam operasional Bandar Udara JB. Soedirman. Perhitungan yang dilakukan disini adalah perhitungan sederhana dalam menentukan biaya operasional. Bagan alir studi ditunjukkan pada Gambar 1.

\section{ANALISIS DATA}

\section{A. Prediksi Permintaan Angkutan Udara}

Dalam memprediksi permintaan angkutan udara pada andara JB. Soedirman menggunakan analisis regresi, dengan data awal adalah data skenario penumpang oleh BAPPEDA Purbalingga yaitu 174,758 pnp/tahun. Selanjutnya dilakukan analisis terhadap 4 kabupaten yang berpotensi menjadi penumpang bandara nantinya seperti ditunjukkan pada Gambar 2, dan hasil dari
Tabel 1. Prediksi Penumpang Bandara JB. Soedirman Tahun 2025

\begin{tabular}{ccc}
\hline No & Kabupaten & Jumlah Penumpang \\
\hline 1 & Banyumas & 78.794 \\
2 & Purbalingga & 42.942 \\
3 & Banjarnegara & 37.370 \\
4 & Wonosobo & 15.652 \\
& TOTAL & 174.758 \\
\hline
\end{tabular}

Tabel 2. Pesawat Regional di Indonesia

\begin{tabular}{|c|c|c|c|c|c|}
\hline No & Tipe & Maskapai & Berat & $\begin{array}{l}\text { Jarak } \\
\text { Terbang }\end{array}$ & $\begin{array}{l}\text { Kapa } \\
\text { sitas }\end{array}$ \\
\hline 1 & $\begin{array}{l}\text { ATR 72- } \\
600\end{array}$ & $\begin{array}{l}\text { Garuda INA } \\
\text { Wings Air } \\
\text { Kalstar }\end{array}$ & 22800 & 1333 & 70 \\
\hline 2 & $\begin{array}{l}\text { ATR 72- } \\
500\end{array}$ & Wings Air & 22000 & 1224 & 68 \\
\hline 3 & $\begin{array}{l}\text { ATR 42- } \\
300\end{array}$ & Kalstar & 18600 & 1165 & 48 \\
\hline 4 & $\begin{array}{l}\text { CRJ } 1000 \\
\text { NextGen }\end{array}$ & Garuda INA & 39222 & 2639 & 104 \\
\hline
\end{tabular}

Tabel 3. Kondisi Lingkungan Bandar Udara [8]

\begin{tabular}{lll}
\hline No. & Kondisi Lingkungan & \\
\hline 1. & Airport Reference Temperature & $27,7^{\circ} \mathrm{C}$ \\
2. & Elevation & $\pm 50,000 \mathrm{~m}(\mathrm{MSL})$ \\
3. & Slope (Kemiringan) rata-rata & $0,05 \%$ \\
\hline
\end{tabular}

Tabel 4. Geometrik Runway

\begin{tabular}{lll}
\hline No & Fasilitas Sisi Udara & Dimensi \\
\hline 1 & Panjang Runway & $1600 \mathrm{~m}$ \\
2 & Lebar Runway & $30 \mathrm{~m}$ \\
3 & Runway Shoulder & $6 \mathrm{~m}$ \\
4 & Blastpad / Stopway & $30 \mathrm{~m} \times 60 \mathrm{~m}$ \\
5 & Runway End Safety Area & $60 \mathrm{~m} \times 90 \mathrm{~m}$ \\
\hline
\end{tabular}

Tabel 5. Geometrik Taxiway

\begin{tabular}{lll}
\hline No & Fasilitas Sisi Udara & Dimensi \\
\hline 1 & Panjang Taxiway & $160 \mathrm{~m}$ \\
2 & Lebar Taxiway & $15 \mathrm{~m}$ \\
3 & Taxiway Shoulder & $25 \mathrm{~m}$ \\
4 & Letak Exit Taxiway & $1359 \mathrm{~m}$ \\
5 & Taxiway Curve & $25 \mathrm{~m}$ \\
\hline
\end{tabular}

perhitungan ditunjukkan pada Tabel 1 [3].

Didapatkan dari hasil analisis regresi jumlah penumpang per tahun pada tahun 2025 adalah 174,758 pnp/tahun.

\section{B. Pesawat Kritis}

Dalam disain ini, direncanakan pesawat yang akan beroperasi di bandara ini adalah pesawat penumpang regional yang biasa digunakan dalam penerbangan regional di Indonesia, berikut tabel pesawat regional yang digunakan oleh maskapai-maskapai yang ada di Indonesia.

Dalam Tabel 2 [4], pesawat ATR 72-600 lebih banyak dipakai maskapai yang ada di Indonesia, mengingat juga bandara ini adalah bandara pengumpan, sehingga tidak memerlukan pesawat yang terlalu besar. Maka untuk Bandar Udara JB. Soedirman akan menggunakan ATR 72-600 sebagai pesawat rencana.

\section{Disain Geometrik Runway}

Dalam perencanaan disain geometrik runway ini menggunakan peraturan yang berlaku yaitu, SKEP/77/VI/2005 [5], ICAO [6]. Dengan peraturanperaturan yang sudah ada maka disain geometrik runway mampu melayani aktivitas penerbangan yang akan dilayani pada Bandara JB. Soedirman ini. Disain geometrik runway ditunjukkan pada Tabel 4.

Berdasarkan kode pengklasifikasian panjang landasan 
pada elemen I sesuai ketentuan Aerodrome Referenec Code (ARC), pesawat ATR 72-600 termasuk ke dalam kode 3C. Untuk menentukan panjang landasan pacu yang terkoreksi maka perlu dilakukan perhitungan koreksi

\begin{tabular}{lllll}
\multicolumn{4}{c}{ Tabel 6. Perbandingan Biaya Operasional } \\
\hline Rute & $\begin{array}{l}\text { Moda } \\
\text { Eksisting } \\
\text { Termurah }\end{array}$ & $\begin{array}{l}\text { Durasi } \\
\text { (jam) }\end{array}$ & $\begin{array}{l}\text { Biaya } \\
\text { Operasional }\end{array}$ & $\begin{array}{l}\text { Biaya } \\
\text { Operasional } \\
\text { per Jam }\end{array}$ \\
\hline PBG-JKT & Kereta & 6,2 & Rp298.919,89 & Rp48.212,89 \\
PBG-BDG & Mobil & 6,2 & Rp478.032,93 & Rp77.102,09 \\
PBG-SMG & Mobil & 5,87 & Rp167.606,93 & Rp28.553,14 \\
PBG-SLO & Mobil & 5,267 & Rp177.728,30 & Rp33.743,74 \\
PBG-YK & Mobil & 4,03 & Rp138.284,56 & Rp34.313,79 \\
PBG-SBY & Kereta & 9,667 & Rp309.335,99 & Rp31.999,17 \\
\hline
\end{tabular}

\begin{tabular}{lllll}
\multicolumn{5}{c}{ Tabel 6. Perbandingan Biaya Operasional (lanjutan) } \\
\hline Rute & $\begin{array}{l}\text { Durasi } \\
\text { Pesawat } \\
\text { (jam) }\end{array}$ & $\begin{array}{l}\text { Selisih } \\
\text { Durasi }\end{array}$ & $\begin{array}{l}\text { Biaya } \\
\text { Operasional } \\
\text { Pesawat }\end{array}$ & $\begin{array}{l}\text { Penghematan } \\
\text { Nilai Waktu }\end{array}$ \\
\hline PBG-JKT & 1,4 & 4,8 & Rp747.168,42 & Rp231.421,88 \\
PBG-BDG & 0,9 & 5,3 & Rp499.683,61 & Rp406.070,99 \\
PBG-SMG & 0,53 & 5,3 & Rp282.839,78 & Rp152.522,25 \\
PBG-SLO & 0,65 & 4,6 & Rp348.835,73 & Rp155.741,81 \\
PBG-YK & 0,52 & 3,5 & Rp278.125,78 & Rp120.458,66 \\
PBG-SBY & 1,65 & 8 & Rp883.369,24 & Rp256.537,36 \\
\hline
\end{tabular}

Tabel 6. Perbandingan Biaya Operasional (lanjutan)

\begin{tabular}{ll}
\hline Rute & BOP - Penghematan Waktu \\
\hline PBG-JKT & Rp515.746,54 \\
PBG-BDG & Rp93.612,62 \\
PBG-SMG & Rp130.317,53 \\
PBG-SLO & Rp193.093,92 \\
PBG-YK & Rp157.667,12 \\
PBG-SBY & Rp626.831,88 \\
\hline
\end{tabular}

Kondisi lingkungan pada Tabel 3 tersebut memengaruhi kebutuhan panjang runway suatu pesawat. Sehingga panjang runway yang diperlukan adalah $1598,9 \mathrm{~m} \approx 1600 \mathrm{~m}$

Koreksi akibat elevasi, Fe

$\mathrm{Fe}=1+0.07\left(\frac{h}{300}\right)=1+0,07\left(\frac{50}{300}\right)=1,012$

Koreksi akibat temperature, $\mathrm{Ft}$

$$
\begin{aligned}
\mathrm{Ft} & =1+0,01(\mathrm{~T}-(15-0,0065 * \mathrm{~h}) \\
& =1+0,01(27,7-(15-0,0065 * 50) \\
& =1,130
\end{aligned}
$$

Koreksi akibat kemiringan, Fs

Fs $=1+(0,1 * S)=1+(0,1 * 0,05)=1,05$

Dari perhitungan koreksi di atas, maka panjang landasan terkoreksi adalah;

$$
\begin{aligned}
\text { Panjang Runway } & =\text { ARFL } \times \text { Ft } \times \text { Fe } \times \text { Fs } \\
\text { Panjang Runway } & =1.333 \times 1,130 \times 1,012 \times 1,050 \\
& =1598,9 \mathrm{~m} \approx \mathbf{1 6 0 0} \mathbf{m}
\end{aligned}
$$

\section{Disain Geometrik Taxiway}

Dalam perencanaan disain geometrik taxiway ini menggunakan peraturan yang berlaku yaitu, SKEP/77/VI/2005 [5], ICAO [6]. Dengan peraturanperaturan yang sudah ada maka disain geometrik runway mampu melayani aktivitas penerbangan yang akan dilayani pada Bandara JB. Soedirman ini, yang menggunakan pesawat kritis ATR 72-600 dengan kelas bandara IIIC dan penggolongan pesawat ATR 72-600 yaitu kelas III.

\section{E. Disain Geometrik Apron}

ARFL pesawat terhadap elevasi, temperatur dan kemiringan landasan (slope), dengan data-data kondisi lapangan ditunjukkan pada Tabel 3.

Pada disain apron dengan menggunakan rumus yang sudah ditentukan untuk menghitung jumlah pesawat yang akan parkir pada apron maka di dapatkan [7];

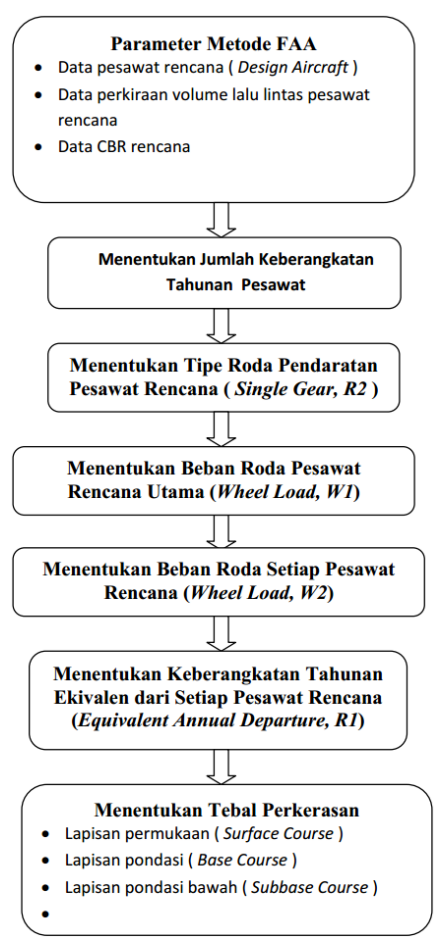

Gambar 3. Bagan Alir Perkerasan Sisi Udara.

$$
\begin{aligned}
& \mathrm{N}=\frac{C \times T}{60}+A \\
& \mathrm{~N}=\frac{1 \times 30}{60}+1 \\
& \mathrm{~N}=2 \text { pesawat }
\end{aligned}
$$

Dimana:

$\mathrm{N}=$ Jumlah pesawat yang akan parkir di apron

$\mathrm{T}=$ Waktu pemakaian gate

$\mathrm{C}=$ Pergerakkan pesawat pada jam sibu(gerakan/jam)

$\mathrm{A}=$ Cadangan pesawat

Kelas C waktu pemakaian gate 30 menit

Dengan direncanakannya apron yang dapat menampung 2 pesawat ATR 72-600, maka kebutuhan luasan apron dapat ditentukan sebagai berikut:

Pesawat ATR 72-600 [8]

Wingspan $=27,05 \mathrm{~m}$

Length $=27,17 \mathrm{~m}$

Clearance $=4,50 \mathrm{~m}(\mathrm{SKEP} / 77 / \mathrm{VI} / 2005)[6]$

Perhitungan :

$$
\begin{aligned}
\text { Panjang Apron } & =(2 \times 27,05)+(3 \times 4,5) \\
= & 67,6 \mathrm{~m} \approx 70 \mathrm{~m} \\
\text { Lebar Apron } & =4,5+27,17+10,5+27,5 \\
& =69,32 \mathrm{~m} \approx 70 \mathrm{~m}
\end{aligned}
$$

Kemudian ditambah untuk jarak bebas ujung wingspan antas pesawat dan tepi apron $15 \mathrm{~m}$, maka di dapatkan lebar total $85 \mathrm{~m}$

\section{F. Disain Rute yang Memungkinkan}


Tabel 7. Hasil Desain Perkerasan dengan Metode FAA (CBR 6)

\begin{tabular}{|c|c|c|c|}
\hline \multirow{2}{*}{ Lapisan } & \multirow{2}{*}{$\begin{array}{l}\text { Bahan yang } \\
\text { Digunakan }\end{array}$} & \multicolumn{2}{|c|}{ Tebal Rencana } \\
\hline & & inci & $\mathrm{cm}$ \\
\hline $\begin{array}{l}\text { Permukaan } \\
\text { (surface course) }\end{array}$ & P-401 & 4 & $10,16 / 11 \mathrm{~cm}$ \\
\hline $\begin{array}{l}\text { Pondasi } \quad \text { (base } \\
\text { course) }\end{array}$ & P-209 & 4 & $10,16 / 11 \mathrm{~cm}$ \\
\hline $\begin{array}{l}\text { Pondasi bawah } \\
\text { (subbase course) }\end{array}$ & P-154 & 10 & $25,4 / 26 \mathrm{~cm}$ \\
\hline
\end{tabular}

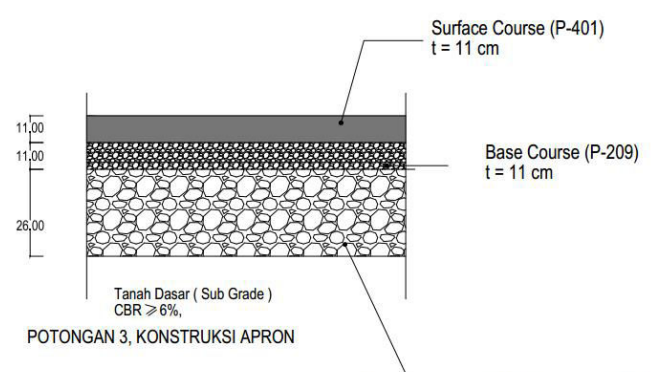

SubBase Course (P-154), $t=26 \mathrm{~cm}(\mathrm{CBR}>15 \%)$

Gambar 4. Potongan melintang perkerasan [4].

Dalam merencanakan rute yang memungkinkan pada Bandar Udara Jenderal Besar Soedirman dilakukan melalui kemampuan jarak terbang pesawat yang sudah direncanakan yang kemudian akan dilakukan perhitungan biaya operasional dari moda kendaraan yang sudah ada, dalam kasus ini yang dibandingkan adalah moda mobil dan moda kereta. Kedua moda tersebut nantinya akan dihitung perbandingannya. Jika moda pesawat akan lebih murah dari moda mobil/kereta, maka rute tersebut akan menjadi rute yang memungkinkan ada dalam operasional Bandar Udara JB. Soedirman. Perhitungan yang dilakukan disini adalah perhitungan sederhana yaitu dengan menghitung biaya yang dihabiskan per-jam mdoa kereta/mobil, kemudian selisi durasi dari moda pesawat dan moda mobil/kereta dikalikan dengan biaya operasional per-jam dari moda mobil/kereta, yang hasil perkaliannya dikurangi dengan biaya operasional pesawat yang dikeluarkan. Tabel 6 adalah hasil perhitungan perbandingan biaya operasional moda termurah dan biaya operasional pesawat.

Pada Tabel 6 yang sudah disajikan, highlight hijau menandakan rute yang memungkinkan dan hightlight merah rute yang tidak memungkinkan, dapat disimpulkan rute yang memungkinkan adalah Purbalingga-Bandung dan Purbalingga-Semarang.

Namun dengan pertimbangan lain terkait rute yang memungkinkan, yaitu dari hasil survei yang sudah dilakukan BAPPEDA Kab. Purbalingga [9] sebelumnya terkait pola pergerakkan dari penumpang yang ada di Kab. Purbalingga, yang respondennya adalah pegawai instansi pemerintah, penumpang KA. Eksekutif di Stasiun Purwokerto, penumpang di Bandar Udara Tunggul Wulung Cilacap, dan pengunjung hotel di Purwokerto. Dari hasil survei di dapatkan 4 tujuan yaitu Jakarta, Semarang, Yogyakarta, dan Surabaya. Maka dapat disimpulkan untuk rute yang memungkinkan adalah sebagai berikut;
a. Purbalingga - Surabaya
b. Purbalingga - Bandung
c. Purbalingga - Semarang
d. Purbalingga - Yogyakarta
e. Purbalingga - Jakarta/Tangerang

\section{G. Disain Perkerasan}

Perencanaan perkerasan dalam studi ini menggunakan metode FAA, Federal Aviation Administration adalah metode yang pada dasarnya menggunakan analisa statistik perbandingan kondisi lokal dari tanah, sistem drainase dan cara pembebanan untuk berbagai tingkah laku beban, dimana topografi, jenis-jenis lapisan tanah serta evaluasi air tanah akan sangat berpengaruh terhadap kondisi yang dihadapi di lapangan, tetapi dalam hal merencanakan tebal perkerasan landasan pacu suatu bandar udara metode ini juga sangat memperhatikan annual departure (tingkat keberangkatan tahunan pesawat) dari pesawat yang akan direncanakan pada perencanaan suatu perkerasan bandar udara. Gambar 3 merupakan bagan alir dari perencanaan perkerasan lentur sisi udara menggunakan metode FAA;

Langkah pertama adalah menentukan tipe roda pendaratan pesawat rencana (Single Gear, $R_{2}$ ), dengan mengetahui keberangkatan tahunan dan faktor konversi roda pendaratan utama.

No 1

Tipe Pesawat ATR 72-600

Forecast Annual Departure (a) 1825

Faktor Konversi Roda Pendaratan Utama (b) 0,6

Single Gear Departure (a x b 1095

Kemudian menentukan beban roda pesawat rencana (Wheel Load, $W_{2}$ ).

ATR 72-600 [10]

$$
\begin{array}{lll}
\text { MSTOW } & =50.705 \mathrm{lbs} \\
\mathrm{A} & =1 \\
\mathrm{~B} & =4 \\
\mathrm{~W}_{2} & =0.95 \times 50.705 \times 1 \times 1 / 4 \\
& =12.042,44 \mathrm{lbs} \\
& \mathrm{W}_{2}
\end{array}
$$

Dimana:

$\mathrm{W}_{2}=$ Beban roda pendaratan dari masingmasing jenis pesawat

MSTOW = Berat kotor pesawat saat lepas landas

A $=$ Jumlah konfigurasi roda

$\mathrm{B}=$ Jumlah roda per satu konfigurasi

$\mathrm{P} \quad=$ Persentasi beban yang diterima roda pendaratan utama

Setelah menghitung $\mathrm{R}_{2}$ dan $\mathrm{W}_{2}$, kemudian dilanjutkan dengan menghitung keberangkatan tahun ekivalen $\left(R_{l}\right)$.

- $\quad$ ATR 72-600 [8]

$$
\begin{aligned}
\log \mathrm{R}_{1} & =\log \mathrm{R}_{2}\left[\frac{W_{2}}{W_{1}}\right]^{1 / 2} \\
& =\log (1095)\left[\frac{12.042,44}{12.042,44}\right]^{1 / 2} \\
& =3,03941412 \\
\mathrm{R}_{1} & =(10) \\
\mathrm{R}_{1} & =1095
\end{aligned}
$$

Menggunakan data data yang didapatkan yaitu $\mathrm{R}_{1}, \mathrm{R}_{2}$, $\mathrm{W}_{1}$, dan $\mathrm{W}_{2}$. Dengan menggunakan grafik yang disediakan FAA [8], di dapatkan tebal minimum perkerasan adalah 16inch. Maka direncanakan sesuai dengan Tabel 7 [10];

\section{H. Disain Saluran Drainase Sisi Udara}

Dalam merencanakan sistem drainase sisi udara ini diperlukan analisis hidrolika dan hidrologi untuk 


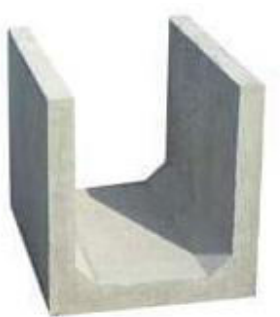

Gambar 5. Saluran U Ditch.

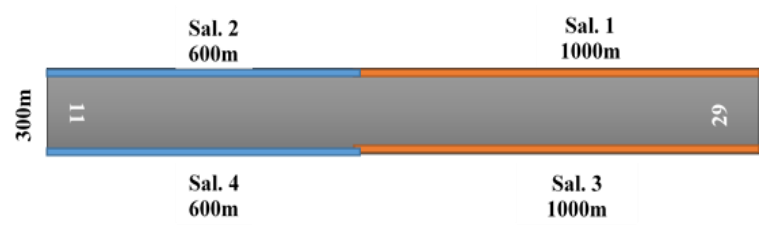

Gambar 6. Ilustrasi Drainase Sisi Udara Bandara JB. Soedirman

menentukan dimensi saluran di sisi udara. Hasil analisis yang sudah dilakukan saluran dibagi menjadi 2 section masing-masing sisi runway strip dan menggunakan saluran U-Ditch milik Inticon seperti pada gambar 5, dengan saluran 1 dan 3 sepanjang $1000 \mathrm{~m}$, dan saluran 2 dan 4 sepanjang $600 \mathrm{~m}$, dengan ukuran secara urut 1400x1200x1200, dan 1600x1850x1200, dengan ilustrasi seperti pada Gambar 6 [3], dan perhitungan seperti pada Tabel 8 .

\section{KESIMPULAN}

Prediksi permintaan angkutan udara sebanyak 174,758 penumpang/tahun pada tahun 2025, hasil perhitungan yang sudah dilakukan oleh penulis didapatkan arah runway adalah 2911 dengan panjang dan lebar runway sebesar $1600 \mathrm{~m}$ dan $30 \mathrm{~m}$ dengan dilengkapi bahu landasan $6 \mathrm{~m}$. Untuk dimensi stopway direncanakan $60 \mathrm{~m}$ x 60m. RESA direcanakan $90 \mathrm{~m}$ x 60m. Disain untuk lebar taxiway sebesar $15 \mathrm{~m}$, panjang $160 \mathrm{~m}$, dengan lokasi exit taxiway $1350 \mathrm{~m}$ dari ujung runway. Luas apron yang dibutuhkan untuk parir pesawat adalah $70 \mathrm{~m}$ x $85 \mathrm{~m}$.

Marka-marka yang dibutuhkan pada sisi udara dimensi/ukuran mengacu pada SNI 03-7095-2005 mengenai marka dan rambu pada daerah pergerakan pesawat udara di bandar udara. Dalam menetapkan kawasan keselamatan operasional penerbangan untuk
Bandara JB. Soedirman mengacu pada ICAO dan juga SNI 03-7112-2005 menganai kawasan keselamatan operasi penerbangan.

Drainase sisi udara pada Bandara JB. Soedirman direncanakan menjadi 2 section menggunakan saluran UDITCH dengan ukuran 1400x1200x1200 sepanjang $1000 \mathrm{~m}$ dan 1600x1850x1200 sepanjang 600m

Untuk rute yang memungkinkan dilayani pada Bandara JB. Soedirman nantinya. Direncanakan menggunakan 2 metode, yaitu metode perbandingan biaya operasional antar moda dan metode wawancara yang dilakukan oleh BAPPEDA Kab. Purbalinga dengan rute yang memungkinkan dengan tujuan Jakarta, Surabaya, Bandung, Semarang, dan Yogyakarta

\section{DAFTAR PUSTAKA}

[1] Republik Indonesia, "Keputusan Direktur Jenderal Perhubungan Udara Nomor: KP 160 Tahun 2017,” 2017. [Online]. Available: http://jdih.dephub.go.id/produk_hukum/view/UzFBZ01UWX dJR1JCU0ZWT01ESXdNVGM9. [Accessed: 20-Mar-2019].

[2] M. Rodiyani, “., Karakteristik Statik, Sinamik dan Resitivitas Karakteristik Statik, Dinamik dan Resistivitas Analisis Potensi Pengoperasian Banda Udara Notohadinegoro," Surabaya, 2015.

[3] M. Y. Permana, "Perencanaan Fasilitas Sisi Udara dan Operasional Bandar Udara Jenderal Besar Soedirman," Surabaya, 2018.

[4] tiket2.com, "Tipe Pesawat Yang Dipakai Oleh Maskapai Penerbangan Indonesia» Tiket2 Indonesia." [Online]. Available: https://www.tiket2.com/blog/tipe-pesawat-yangdipakai-oleh-maskapai-penerbangan-indonesia/. [Accessed: 20-Mar-2019].

[5] D. J. P. Udara, Peraturan Direktur Jenderal Perhubungan Udara Nomor: SKEP/77/VI/2005 tentang Persyaratan Teknis Pengoperasian Fasilitas Teknik Bandar Udara. 2005.

[6] C. Aviation Authority of New Zealand, "ICAO - International Standards - Aerodromes - Annex 14 Vol 1 Amendment 11."

[7] HERU BASUKI, Buku Merancang, Merencana Lapangan terbang Oleh Ir Heru Basuki. 1986.

[8] ATRaircraft,

";http://www.atraircraft.com/datas/download_center/27/fiche 72_27.pdf," $2017 . \quad$ [Online]. Available: http://www.atraircraft.com/datas/download_center/27/fiche72 _27.pdf.

[9] BAPPEDA Kab. Purbalingga, "Pola Pergerakkan Penumpang Kabupaten Purbalingga," 2014.

[10] F. Airport Engineering Division, "AC 150/5320-6E, Airport Pavement Design and Evaluations, 30 September 2009," 2009. 